\title{
The process of endogenous liquidity in developing economies: the case of Mexico*
}

\author{
Luis Alfredo Castillo Polanco** \\ Universidad de Quintana Roo, Chetumal, Mexico \\ Ted P. Schmidt*** \\ Department of Economics and Finance, The State University of New York, Buffalo, NY, USA
}

The Post-Keynesian theory of endogenous money is typically used to explain the operations in advanced economies like the US. While the core ideas are relevant for all market economies, developing economies have additional features which complicate the process. These may include: the local currency is not accepted as a means of payment for international transactions, so the banking system (including the central bank) requires foreign currency reserves (balance-of-payments constraint); hard currency reserves are needed to provide 'credibility' for circulation of domestic currency; stock and bond markets are not well developed, so other financial instruments are necessary to complete the finance-funding process; and institutional differences regarding monetary control.

We use the case of Mexico to show how these features of developing economies can complicate the endogenous-money process. For Mexico the process is constrained by the use of the US dollar as both a store of value and a reserve for the banking system. As a consequence, the interest rate is determined by the demand for the alternative sources of liquidity creation, and therefore a credit-financed expansion will necessitate an increase in the interest rate which can lead to a recession or other crisis scenarios.

Keywords: endogenous money, Thirlwall's law, Mexico, US dollar, peso, Mexican banking system

JEL codes: $E 12, E 580, F 43, O 240$

\section{INTRODUCTION}

Post-Keynesian theories of the finance-funding process and endogenous money are oriented toward explaining the money-creation/destruction process and its effect on economic performance. While there may be differences in the way the main variables in the theories operate, the models are usually developed as a closed-economy, singlecurrency case. Perhaps this is because they were originally developed to explain the American and British economies?

* The authors wish to thank the anonymous reviewers for their constructive recommendations and suggested corrections which greatly improved the paper. Any remaining errors are our own.

** Email: Alfredo_c_p@yahoo.com.

*** Email: schmidtp@buffalostate.edu. 
We argue that the fundamental Post-Keynesian theory of endogenous money developed for a single-currency advanced country does not adequately explain the process for many developing market economies. Specifically, there are institutional features of developing economies that complicate the endogenous-money process, and we explicate the differences through a case study of Mexico.

The critical difference between Mexico and the advanced-country case is that the domestic currency (the peso) does not meet the store of value function; rather, this is the role of the US dollar (US\$). As a consequence, as the economy and peso circulation grow, the banking system needs US\$ reserves to support the store of value demand, creating an additional constraint on liquidity creation compatible with Thirlwall's law (Thirlwall and Dixon 1979; Thirlwall 2011). Given the balance-of-payments $(\mathrm{BoP})$ constraint, we argue that the interest rate is influenced by the dominant source of liquidity alternatives (domestic versus international); and, as opposed to the singlecurrency case of advanced countries, an expansion of domestic currency will be followed by an increase in the interest rate (to meet US\$ needs) which can foster crisis scenarios. Finally, given that Mexico's capital markets are not widely used by the population, capital instruments do not provide the main liquidity cancelling instruments; rather, this is the function of savings deposits.

We include all of these features to show that the standard endogenous-money explanation for advanced economies is not compatible with the endogenous-money process in a developing economy like Mexico. In particular, we show how these institutional differences create additional constraints on the endogenous-money process. The endogenous liquidity process that we describe refers to the mechanisms used to inject liquidity from alternative sources of local and foreign credit and to withdraw liquidity through amortizations and savings deposits in the banking system, as opposed to private capital market instruments. While these mechanisms operate to constrain or expand aggregate spending, changes in aggregate demand are expressed in domestic markets through changes in total peso liquidity, which can arise from either domestic or foreign sources.

In Section 2 we lay out in detail the institutional differences between Mexico and the advanced-country case. In Section 3 we define the terms used to test the relationships proposed in the paper. In Section 4 we evaluate and test the following hypotheses: one, the peso is used as a medium of exchange only; two, liquidity growth is constrained by US\$ flows; and, three, the interest rate is determined by the balance of internal reserve (peso) versus external reserve (US\$) demands. We conclude in Section 5 with policy implications and future research considerations.

\section{ENDOGENOUS MONEY AND INSTITUTIONAL DIFFERENCES IN MEXICO}

While Post-Keynesian economists agree money is endogenously determined by demand-driven credit, differences still persist with regard to the mechanisms underlying this result, especially with respect to the interest-rate determination process. ${ }^{1}$ Despite these differences, most literature on endogenous money shares an institutional framework that refers to a developed economy, where the only (at least the dominant) source of money is domestic commercial bank credit.

1. For a recent discussion on the history of Post-Keynesian endogenous-money theories, see Rochon and Rossi (2013). Regarding arguments surrounding interest rates - liquidity preference vs mark-up approach - see Rousseas (1985) and Wray (2004). 
In the Post-Keynesian finance-funding theory (based on Keynes's revolving fund theory), money is created by banks in order to finance new investment; the concomitant spending creates savings (or deposits) which are the source of funds used to buy new (financial) capital instruments sold by debtors who use the funds to pay off bank credit, thus completing the finance-funding process. There are certainly differences among Post-Keynesians regarding the degree to which the banking system can create and meet all credit/money demanded, but these issues become irrelevant once the finance-funding process is completed. ${ }^{2}$ Regarding the funding process, it is typically assumed that there are deep and broad capital markets, so a significant amount of bank credit is eventually converted into long-term instruments, which implies that other bank deposits are less significant for the finance-funding process. At the extreme, the only constraint to full employment in a limitless endogenous-money world is the demand for loans driven by the 'animal spirits of the entrepreneur.'

Since Post-Keynesian theories typically focus on the closed-economy case, by definition deposits of foreign currency in local banks are not considered; however, these deposits can be, and have been, the cornerstone of the banking system for some developing countries. In the following sections we outline the US\$'s role in the Mexican banking system and other institutional differences that make the endogenous-money process in Mexico distinctly different from the advanced-country case.

\subsection{Economic crises and the dollar as a store of value}

To be considered money, in addition to meeting the medium of exchange function, a financial asset must be used to cancel debts and meet store-of-value functions, like the speculative and precautionary motives. Even when the definition of money is restricted to coins, bills, and bank demand deposits - narrow money - it is still subject to store-of-value functions. In the case of Mexico, however, the store-of-value function is expressed as a demand for US dollars. There are three reasons for this: first, higher inflation in Mexico tends to devalue the peso relative to the dollar, so the US\$ preserves purchasing power better than the peso; two, Mexico is highly dependent on the import of capital goods and the peso is not accepted for these international transactions; and, three, wealthy Mexicans have a long history of holding US bank accounts, and moving dollars out of the country is relatively simple.

The shift toward neoliberal economic policies in the 1980s and the first half of the 1990s brought about important changes to the institutional framework in Mexico: the economy became more open to foreign trade (through the General Agreements on Tariff and Trade (GATT) and the North American Free Trade Agreement (NAFTA)); national banks were privatized; the fractional reserve banking system was eliminated; the central bank could no longer directly make loans to the government; and austerity policies pushed fiscal deficits toward balance.

As the focus of the Mexican growth model shifted to the neoliberal model, there were two important structural changes of note. First, the focus of Mexico's export sector shifted from primary products to technology-intensive goods. From 1962 to 2015 , primary products fell from 37.5 percent to 5.5 percent of total exports, whereas technology-intensive products increased from 2 percent to 65 percent (Araujo et al. 2016). Second, having been nationalized after the 1982 financial crisis, the Mexican

2. For example, there is debate among Post-Keynesians regarding the degree to which banks can meet loan demand without central-bank accommodation; see Pollin (1991). 


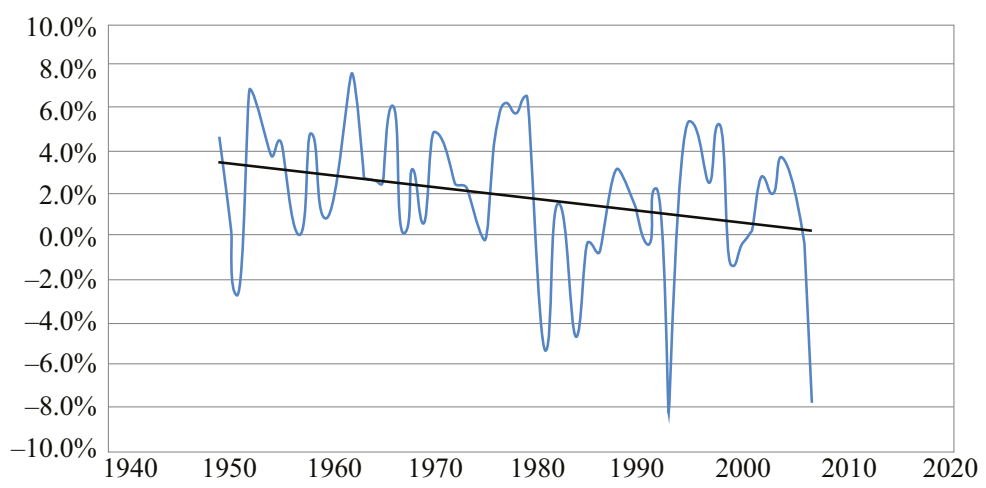

Source: Banxico and Instituto Nacional De Estadistica y Geografia (INEGI).

Figure 1 Real GDP per capita

banking system began a process of reprivatization in the 1990s, and 'NAFTA also promoted the Mexican financial system to adapt to the financial organization of the US' (Levy-Orlik and Dominguez-Blancas 2016, p. 532). More importantly, toward the end of the 1990s, four of the largest privately owned Mexican banks were acquired by foreign banks, increasing foreign ownership from 6.25 percent of total assets in 1995 to 43 percent in 2000, and 73 percent by 2011 (ibid., p. 533).

Despite the rhetoric that neoliberalism would improve the Mexican economy, the reforms had serious negative consequences. Figure 1 shows the rate of growth of real GDP per capita in Mexico over the past 60 years. Trend growth in RGDP averaged about 2 percent until the end of the 1970s, but has averaged close to zero since 1980 , the beginning of the neoliberal period. In addition, there have been recurrent economic crises $(1982,1986,1995,2001$, and 2008), and the concomitant inflation-devaluation of the peso instigated periodic episodes of capital flight from the peso to the US\$, establishing the latter as the preferred store of value for Mexicans. For Mexico, then, the most important institutional differences with advanced countries are that the peso is used as the unit of account and the domestic medium of exchange, while the US\$ is the preferred store of value and the medium of exchange for international transactions.

\subsection{Foreign currency as a necessary bank reserve}

The Mexican economy is considered part of the dollar zone. Since the peso is not accepted as a means of payment in international commerce and Mexico's largest trading partner is the US, the US\$ is the most important foreign currency required for international transactions. On the other hand, the Mexican peso is widely used for almost all domestic transactions in the country. The US\$'s role as the store of value gives rise to the critical institutional difference for the Mexican banking system: both the peso and the US\$ are required as reserves to support the growth of credit (Castillo-Polanco 2012). The standard assumption of endogenous-money theory, that commercial banks need only to obtain (domestic) central-bank reserves to support credit (and money) creation, ignores this hierarchical character of money in a developing economy such as Mexico. 
Banks in Mexico hold significant amounts of US\$ reserves to satisfy foreign commerce needs and to make their customers believe the required dollar reserves are available if there is a run on the peso. The central bank of Mexico (Banxico) is no exception. In fact, the central bank must maintain a significant amount of foreign currency reserves as a collateral guarantee for its international debt. Figure 2 shows the evolution of commercial and central-bank US\$ liquid foreign reserves (cash and deposits abroad) in relation to total liquidity, which includes the central bank's monetary base $(B)$ plus demand deposits in commercial banks $(D D){ }^{3}$

The Mexican economy operates with open international markets (both commerce and capital) and unrestricted convertibility of pesos into dollars (a floating exchange rate). As part of the dollar zone, international reserves held by the Mexican central bank are important because they guarantee the free conversion of pesos into US\$. In addition, international reserves are required by commercial banks to meet the needs of multinational corporations operating in Mexico, and because wealthy Mexicans prefer to hold US\$ deposits as a store of value. ${ }^{4}$ Use of the US\$ for both commerce and as a store of value gives rise to the key institutional difference for the endogenous-money process in Mexico: when commercial banks create credit to meet the demands of an expanding economy, they must obtain both central-bank reserves (pesos) and foreign-currency reserves (US\$), otherwise the risk of a banking crisis increases.

Given its proximity and openness to the US, relatively large amounts of US\$ are deposited in Mexican commercial-bank accounts, and these US\$ flows can be used to increase more than proportionally the domestic peso deposits in local banks. ${ }^{5}$ In the case of Mexico, domestic credit can be expanded by the banking system from an increase in either pesos or US\$ reserves.

According to Thirlwall (2011), the BoP can create a constraint on economic growth, and this is especially true for less developed countries that rely on exporting primary products

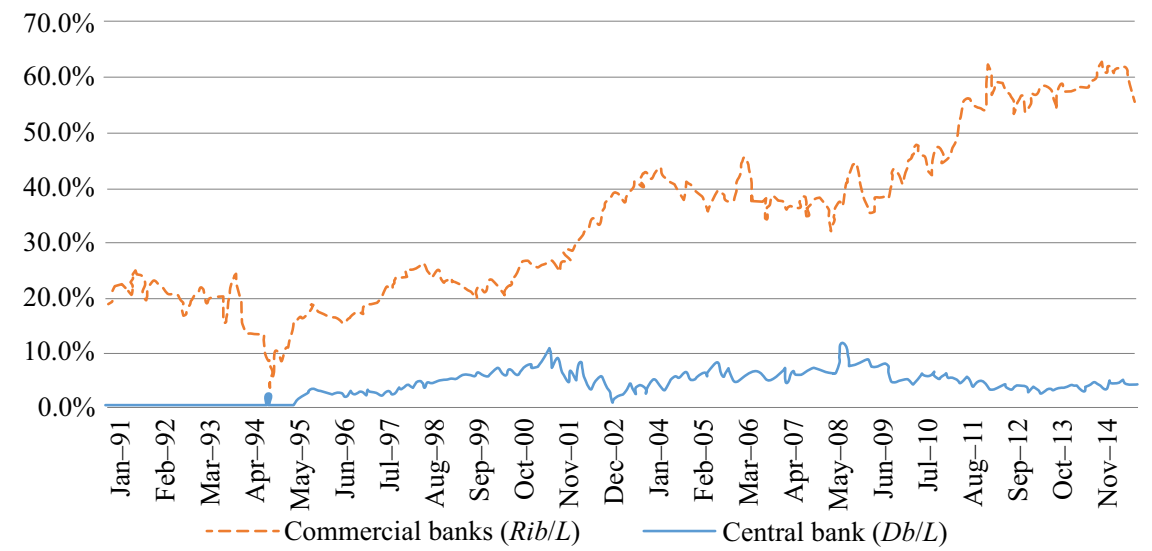

\section{Figure 2 US dollar reserves}

3. We formally define Liquidity, Rib/L, and $D b / L$ in Section 3.

4. Wealthy Mexicans (and multinational corporations) maintain US\$ accounts in Mexico and outside the country, so Mexican commercial banks must hold a sufficient supply of dollars to meet their domestic needs and/or their desire to transfer US\$ to foreign accounts.

5. The US\$ is also used for local commerce in border and tourist regions. 
relative to manufactured products, as Prebisch (1949) argued. ${ }^{6}$ Countries that experience persistent current-account deficits need foreign currency to finance those deficits, and exports are the ultimate source of foreign exchange in the long run. Consequently, if the growth of exports does not generate sufficient foreign exchange, then the rate of economic growth (and therefore imports) must decline in order to balance the current account.

In the case of Mexico, given that the export sector uses a significant level of imported intermediate goods, much of the recent literature evaluating BoP-constrained growth has utilized a multi-sector analysis; however, the results have been inconsistent (see, for example, Gouvêa and Lima 2010; Ibarra and Blecker 2014; Araujo et al. 2016). Blecker and Ibarra (2014) suggest that the dramatic structural changes in the Mexican economy over the past 40-50 years provides an explanation for the inconsistent results. When testing for the underlying elasticities of exports and imports, they found several structural breaks in the data, suggesting five distinct periods of growth, with some periods exhibiting stronger connections to BoP-constrained growth, and other periods less so. ${ }^{7}$ One of their conclusions, pertinent to the argument in this paper, is that Mexico's growth rate during the post-NAFTA period consistently underperformed BoP-constrained growth estimates:

An increase in the BOP equilibrium growth rate may not lead to an increase in actual growth if other restrictions on growth become more important, as seems to have characterized the situation in Mexico in the immediate post-NAFTA years. In other words, although it may not be sustainable for an economy to grow faster than its BOP-constrained rate, it may be quite possible for an economy to grow below its BOP-equilibrium rate for a sustained period of time. (Blecker and Ibarra 2014, pp. 32-33, emphasis added)

We argue that the need for US\$ reserves by the banking system since the 1995 crisis creates another restriction on growth for the Mexican economy. ${ }^{8}$ While Thirlwall's law suggests a long-term growth constraint from the BoP, the demand for US\$ reserves by the banking system creates a short-term (cyclical) constraint on credit creation, and, therefore, economic growth.

\subsection{Mexican capital markets and the finance-funding process}

Another important institutional characteristic missing in the Mexican economy is the lack of broad and deep capital markets which provide the ultimate instruments to 'fund' long-term investment and cancel liquid credits. ${ }^{9}$ The finance-funding process is expressed by Keynes's revolving fund theory (Keynes 1937, quoted in Cardim de Carvalho 1997, pp. 463-464):

The entrepreneur when he decides to invest has to be satisfied on two points: firstly, that he can obtain sufficient short-term finance during the period of producing the investment; and secondly, that he can eventually fund his short-term obligations by a long-term issue on satisfactory condition.

6. More formally, less developed economies can suffer from BoP-constrained growth because the income elasticity of exports (mainly primary products) is less than the income elasticity of imports (mainly manufactured products).

7. For example, during what they term the NAFTA period, from 1994-2000, exports of manufactured goods grew by 16.2 percent per year, but GDP growth was offset by imported intermediate goods growing by 13.3 percent per year.

8. Ibarra and Blecker (2014) suggested some of the 'other factors' include a slow-down in US growth and rising competition from Chinese exports.

9. See, for example, Levy-Orlik (2012). 
In the revolving fund theory, banks provide ex ante financing (short-term credits that create new deposits) in order to fund new investment expenditure which creates the income and saving ex post. The 'funding process' is completed when the savings are funneled into capital instruments by other financial markets/institutions (investment banks, for example). As Davidson (1986, p. 101) elaborated:

[T] he role of the banking system whose function it is to create additional short-term finance whenever entrepreneurs wish to increase the flow of real investment [is a] bank-created (non-resource using) finance [that] must be distinguished from the role of long-term financial markets which require the public to give up an amount of liquidity equal to real savings (i.e., unexercised income claims on resources) in the process of funding the investment.

The Post-Keynesian revolving fund theory suggests that the link between income and saving occurs when firms issue long-term securities to cancel the bank credit which initially financed investment spending. Since capital markets do not play a significant role in the funding process for the Mexican economy, the consequent cancellation of excessive peso liquidity must take another form. Peso deposits created through credit creation can be withdrawn in one of three forms: shifted into non-transaction bank deposits (NMDs); converted into US\$s; or used to acquire monetary regulation government bonds.

For the majority of Mexican families, the primary portfolio decision for reducing peso demand deposits takes the form of NMD or US\$ deposits, consequently the funding process described by the revolving fund theory does not adequately describe the mechanisms of liquidity cancellation in Mexico. ${ }^{10}$ NMDs operate as peso savings and liquid reserves, and, while they do not cancel deposits (as in the case of credit amortizations), they act to withdraw peso liquidity from circulation, reducing the narrow stock of money. ${ }^{11}$ Wealthier Mexican families, on the other hand, have broader portfolio choices; however, given the lack of deep (private) capital markets, they more often drain excess liquidity via US\$ accounts and government bonds. ${ }^{12} \mathrm{We}$ argue, then, that NMDs and the conversion of pesos into dollars are the operative savings decisions by families that assure the stock of liquid pesos in circulation is proportional to Mexican GDP (PIB). ${ }^{13}$

In the case of Mexico, we argue that the level of aggregate demand endogenously determines the desired stock of peso liquidity (in relation to its velocity of circulation), with excess liquidity drained by NMDs (the main instrument of saving for the majority of the population) and the proportion converted into dollars (mainly by middle and upper-class Mexican families).

\section{DEFINITION AND MEASURE OF LIQUIDITY}

Since the Mexican banking system requires both peso and US\$ reserves, we expand on the narrow definition of money (M1) by adding peso bank reserves to the measure - what we

10. Real estate is also an important asset in the portfolios of many Mexican families.

11. The NMD liquidity withdrawal mechanism is complementary with amortizations that occur when there is liquidity in excess of commercial needs. Reduction of liquidity via amortization is called the reflux mechanism. As Lavoie (2001, p. 229) states, 'if agents wind up with money that they do not want to spend, they will use it to reduce their debt'.

12. These actions tend to be associated with credit created to fund merger and acquisition (M\&A) activity, where the resulting liquidity flows toward wealthy families.

13. In Spanish, the acronym for GDP is PIB, Producto Interno Bruto. 
call liquidity $(L) .{ }^{14}$ We do this to facilitate one of the primary statistical tests in Section 3.4: specifically, the hypothesis that changes in the interest rate depends upon the relative demands for peso and US\$ reserves. In order to test the relationship, we define measures that separate these two stocks. In the next section we evaluate the balance sheets of the commercial banking system and central bank in order to delineate the factors influencing liquidity.

\subsection{Domestic and foreign sources of liquidity}

We use standard balance-sheet accounts of the central bank and a 'representative' commercial bank to account for the alternative sources of liquidity. The balance sheet for commercial banks is given by the following identity:

$$
C R+G S b+H b+R b p+R i b=D D+N M D+C r b x+E,
$$

where $C R$ equals non-bank private-sector loan balances; GSb is the 'portfolio of titles' held by banks, mainly federal government securities; $H b$ equals peso vault cash; $R b p$ equals voluntary (since there are no reserve requirements) peso reserves held at the central bank; ${ }^{15}$ Rib equals US\$ vault cash reserves and other dollar assets on demand (for example, deposits held in foreign banks); $D D$ equals demand deposits; $N M D$ are (mainly) non-transaction time and savings deposits and other liabilities; Crbx equals borrowing from the central bank; and $E$ is bank capital. Rearranging and solving for $D D$, we get:

$$
D D=(C R-N M D)+R i b+[H b-(C r b x-R b p)]+(G S b-E) .
$$

Demand deposits are endogenously created as banks expand credit $(C R)$, the level which is affected by the savings decisions of households to hold NMDs (that is, to the extent $C R>N M D$ ). In order to achieve the conditions that support increased circulation of $D D$, banks need additional US\$ reserves $(R i b)$, and they use financial instruments to obtain the required foreign reserves. In equation (2), the net portfolio operations to acquire US\$ reserves is included in the expression $(G S b-E)$. Banks also need peso vault reserves, $H b$. To satisfy this condition, they usually maintain reserves on demand held at the central bank, and they can also obtain credit from the central bank. These operations are included in equation (2) by the expression $(H b+R b p-C r B x)$.

Next, we consider the central-bank balance sheet:

$$
F x+C r B x+T+O R N=B+R b p+G S c b,
$$

where $F x$ equals the foreign currency reserves of the central bank; $T$ is the portfolio of owned titles; $O R N$ is a catchall variable which includes all other financial assets

14. We use a capital $L$ to indicate the measure of liquidity defined here, and we use a lower case $l$ to represent the general term.

15. We thank an anonymous reviewer for pointing out that voluntary reserves at the central bank 'have been growing substantially although they play a minor role in overall bank reserves.' These reserves perform an important role in how interbank settlements are carried out, and, for November 2015, they amounted to almost 6 percent of $D D$. 
minus all other liabilities; $B$ is the monetary base; and $G S c b$ are monetary regulation liabilities. ${ }^{16}$ The monetary base consists of $H b$ plus $H p u b$, where the latter is the stock of peso currency in circulation. From (3), the monetary base can be expressed as:

$$
B=F x+(T-G S c b+O R N)+(C r B x-R b p) .
$$

Since there are no mandatory reserves, the central bank effects monetary policy through international reserves $(F x)$, open-market operations $(T-G S c b+O R N)$, and lending operations $(C r B x-R b p)$.

As stated, we define total peso liquidity as the sum of demand deposits plus the monetary base:

$$
L=B+D D
$$

Substituting identities (2) and (4) into (5), we obtain:

$$
L=(C R-N M D)+(R i b+F x)+[(G S b-E)+H b+(T-G S c b)+O R N] .
$$

Liquidity, therefore, has three potential sources: (i) credit creation by banks ( $C R-N M D)$; (ii) US\$ inflows $(R i b+F x)$; and (iii) central-bank actions through all other portfolio operations, $[(G S b-E)+H b+(T-G S c b)+O R N]$.

Lastly, we separate liquidity into two components in order to highlight the influences from the competing sources of reserves, pesos, and dollars:

$$
L=L n+L x,
$$

where $L n=(C R-N M D)$ and $L x=(R i b+F x)+[(G S b-E+H b+(T-G S c b)+O R N]$. $L n$ represents the creation of new peso-denominated demand accounts induced by bank credit expansion, and it is influenced by household savings decisions in the form of NMD. $L x$ summarizes the remaining operations from equation (6), with the main component consisting of the actions to acquire US\$ $(R i b+F x)$.

Liquidity has two important distinctive characteristics: first, it is used almost exclusively for transactions in the domestic market; and, second, the growth of $L$ is restricted by the level of US\$ reserves in the banking system. Certainly, credit markets exist in Mexico that issue short- and long-term instruments denominated in pesos, but liquidity is used almost exclusively as the medium for commercial exchange since US\$ deposits fulfill the store-of-value function. Post-Keynesians have shown the amount of money in circulation is defined by an endogenous process that creates and destroys bank credit. In the case of liquidity creation in Mexico, this process must include the US\$'s role as a reserve currency in the banking system.

\subsection{Local and foreign credit as the main sources of liquidity creation}

The main component of $L x$ arises from domestic liquidity generated by US\$ flows into Mexico derived from international transactions. In this sense, $L x$ is endogenously

16. Monetary regulation liabilities are mainly composed of deposits required to repay government securities 'placed by the Central Bank with monetary policy purposes' (www.banxico.org.mx, 28 July 2017). 


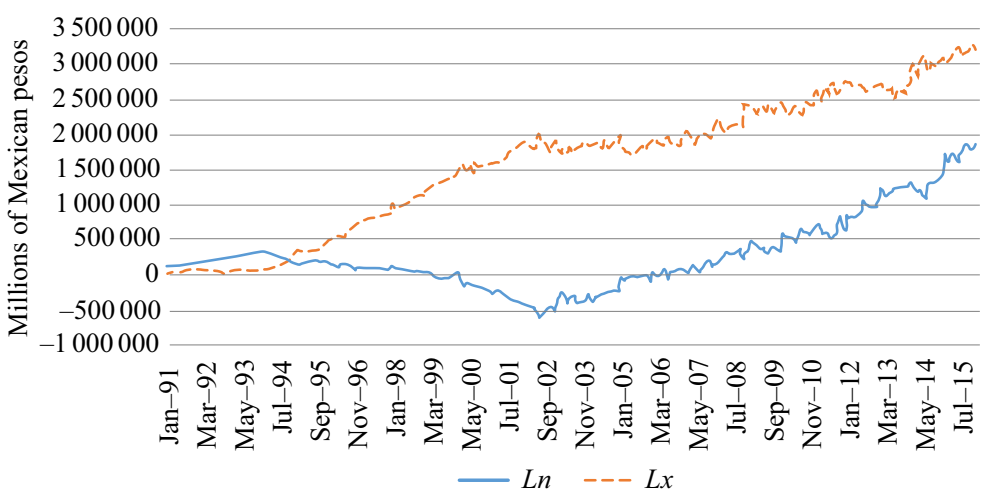

Figure 3 Sources of liquidity

determined since it is not under the control of Banxico. Ln represents traditional credit-driven liquidity creation, increasing when net loan creation increases, and decreasing when the public shifts funds into NMDs. Liquidity cancellation also occurs when credit is repaid (amortizations) or when national currency is converted into US\$. These latter forms of cancellation are not explicitly presented in identity (6); rather, they are considered implicitly since $C R$ and $L x$ are net stocks of liquidity creation. The central bank can withdraw liquidity from circulation using open-market operations and the impact will be reflected in $L x$; however, this does not imply Banxico can control the amount of liquidity in circulation because it does not control US\$ flows.

Figure 3 shows the evolution of the alternative sources of liquidity in Mexico. After the banking crisis of 1995, US\$ inflows became the most important source of liquidity for the Mexican economy. Prior to the recurrent crises, international reserves were mainly derived from international credit to Mexican commercial banks; however, since international reserves cannot be obtained without cost, there is a link between liquidity, the interest rate, and international reserves. We discuss this relationship in the next section.

\subsection{Endogenous liquidity and interest rates}

In the Post-Keynesian theory of endogenous money, commercial banks first create credit then attempt to acquire the necessary reserves to support circulation of increased deposits. The operative institutional difference for Mexico is commercial banks require both peso reserves from Banxico and US\$ reserves generated from foreign inflows; therefore, the actions of commercial banks to obtain peso and US\$ reserves are related to the demand for alternative sources of liquidity ( $L n$ and $L x$ ) and the corresponding level of the domestic interest rate. Consequently, even though the main Post-Keynesian principles are retained, the particular institutional circumstances of the Mexican economy define a process that suggests the source of liquidity used at any moment is connected to a corresponding interest rate (we describe these connections in Section 3.4). In many respects, this process is different from those presented in the Post-Keynesian literature, including open-economy analysis. 
Let us begin with an extreme case analysed in the Post-Keynesian endogenousmoney literature, the situation that occurs when commercial banks have created so much credit that peso reserves created from the fiscal deficit are insufficient to satisfy the reserve needs of commercial banks and the central bank refuses to supply it. Thinking of this possibility, Wray (1998, p. 105) states:

[S]till, one could argue that the central bank could hold fast in a situation of deficit reserves, allowing interest rates to rise as high as necessary to force banks to economize and perhaps even shrink their balance sheets by selling assets. Note, however, that sales of assets cannot actually increase aggregate reserves (except in the unlikely event that households use cash hoards to buy bank assets) and that the demand for reserves is interest-inelastic. Thus, the impact on overnight rates could be very great and a high degree of instability would have to be accepted as the consequence of central bank refusal of reserves.

Certainly, in an 'extraordinary' decision, Banxico can try to define a target level of its monetary reserves $(B)$ with the objective to reduce $D D$. If this hypothetical policy were applied in the current floating exchange-rate environment, Banxico could either refuse to accumulate foreign reserves or it could accept reserves, then use open-market operations to sterilize them. In the former case, since foreign reserves operate as collateral for international debt, refusing to accumulate foreign reserves increases the risk perceived by foreign lenders and therefore the corresponding interest rate. If Banxico chooses the sterilizing option (to reduce $B$ ), then selling bonds would tend to increase interest rates. The central bank must balance its policy of targeting the overnight interest rate with providing pesos to banks on demand.

Liquidity created by Banxico is also endogenous. We defined $L$ by integrating the balance sheets of commercial banks with the central bank, so peso liquidity created by the central bank (included as variable $B$ ) is not analysed independently of the total liquidity created. We assume that $B$ responds passively to demand from the commercial banking system, as endogenous-money theory suggests.

Since the 1995 crisis, monetary policy in Mexico has been conducted by targeting the overnight interbank lending rate, Tasa de Interés Interbancaria de Equilibrio (TIIE). However, Banxico's domestic target rate is also influenced by the pressures that arise from the demand for US\$. The central bank cannot fight the external forces for a long time because it could lead to an economic crisis. In fact, it is one of the main contentions of this paper that the process of liquidity creation in Mexico is constrained by the demand for US\$ which pressures the central bank to move its target interest rate in the way these forces dictate.

Since the 1995 crisis, the principal source used to obtain national and foreign reserves by private banks in Mexico has been US\$ international credit. In addition, as discussed in the next section, the demand for reserves is not interest-inelastic because an increase in the interest rate induces the substitution from liquidity generated by domestic credit $(L n)$ to liquidity generated by foreign flows $(L x)$, and this substitution both reduces domestic credit demand and satisfies commercial banks' demand for US\$ reserves.

The Mexican economy is unable to self-finance its development because an expansion cannot be sustained through national credit without proportional responses of the interest rate and the rate of exchange. As noted by Ibarra and Blecker (2014), GDP growth in Mexico was considerably below the BoP-constrained growth estimate from 1994 to 2000, and it has been moderately lower post 2000, suggesting 'other' constraints on growth. We argue, as peso credit rises in an expansion, the demand for US\$ reserves by the banking system puts upward pressure on the rate of interest, 
creating a short-term (cyclical) constraint on growth akin to Thirlwall's law. We discuss the operative channels that link liquidity with the interest (and exchange) rate in the next section.

\subsection{The relation between sources of liquidity and interest rates}

We argue that the interest rate and the dominant source of liquidity are jointly determined. Specifically, if domestic bank credit increases without a complementary increase in US\$ inflows, the increased demand for US\$ reserves will cause the interest rate to rise in order to encourage substitution of liquidity generated by domestic credit $(L n)$ with liquidity originated through foreign flows $(L x)$. While this substitution is operating, the interest rate will gradually decrease and the substitution between sources of liquidity will be reversed.

We will evaluate the proposition using the accounting identity $L=D D+B=C R-$ $N M D+L x$ (from equations (5)-(7)) to define the net account of the public with the banks (SNPU by Spanish abbreviation):

$$
S N P U=D D+N M D-C R=L x-B=R i b+(H b-(C r b x-R b p))+(G S b-E) .
$$

Identity (8) allows us to observe the correspondence between the movements in $C R$ and commercial banks' reserves. Changes in $S N P U$ are caused by the underlying alternative sources of liquidity: when $S N P U$ increases, $L x$ is the dominant source of liquidity; and when $S N P U$ decreases, domestic bank credit $(C R)$ is the dominant source over the period considered.

For the Mexican banking system, the interest rate operates as a switch that indicates the predominant source of liquidity which is expressed through the relationships embodied in SNPU. Following Castillo-Polanco (2012), we identify the main channels in the process of liquidity creation from an expansion induced internally $(\mathrm{Ln})$ compared with an expansion induced externally $(L x)$.

1. Commercial bank credit creation Endogenous-money theory states that when a bank creates a loan $(C R)$, a corresponding deposit $(D D)$ is created, so the value of $S N P U$ is unchanged. However, as new liquidity circulates, the public's demand rises for both pesos and US\$, with the latter used for imports or to invest abroad. As peso $(\mathrm{Hb})$ and US\$ (Rib) reserves are drained, ceteris paribus, SNPU declines. Given the policy of Banxico is to maintain the overnight interest-rate (TIIE) target, commercial banks can satisfy their peso reserve needs without influencing interest rates. On the other hand, to meet US\$ reserve needs, commercial banks can either acquire them in the domestic foreign-exchange market or borrow from abroad. In the first case, the increased demand for US\$ will tend to weaken the peso, which will increase dollar financing costs. Borrowing US\$ internationally will also raise banks' cost of funds. As funding costs rise, they will be passed along to the public in the form of higher rates on commercialbank loans. Higher interest rates are a response to commercial banks' need to replenish international reserves, and, as both US\$ and peso reserves are increased over the cycle, $S N P U$ increases. Certainly, Banxico could try to accommodate the demand for US\$ from its reserves, but their capacity to 'smooth' the reduction of foreign flows is limited since international reserves operate as collateral for government debt. 
2. Injection of US\$ flows Given an injection of US\$ flows, US\$ deposits at commercial banks increase and some are converted into peso deposits, so both $D D$ and $R i b$ increase, causing SNPU to increase. With additional US\$ reserves, banks can either sell dollars in the local foreign-exchange markets, causing the peso to strengthen, or they can pay down foreign debt. ${ }^{17}$ In either case, funding costs decline, and competitive pressures will reduce the interest rate on commercial bank loans. To be clear, the beginning of a US\$-induced credit cycle will see an increase in Rib and SNPU associated with a lower interest rate. However, as the credit expansion cycle ensues (and liquidity rises), the demand for US\$ and peso reserves increases, and $S N P U$ will rise along with interest rates in a similar fashion to a domestic-induced credit expansion.

To illustrate the cycle, consider a situation where a rise in oil prices increases the flow of US\$ into the Mexican banking system: dollar reserves are plentiful (Rib increases), interest rates decline, and an expansionary credit cycle begins. US\$ reserves are sufficiently abundant in the early stages of the credit cycle, so a positive change in the value of $S N P U$ is associated with lower interest rates. As credit expansion continues, the additional US\$ reserves are drained (to fund imports or invest abroad) and the public's demand for peso reserves is rising (increasing $B$ ), the latter of which is supplied by Banxico at the existing interest rate. As the level of US\$ reserves (Rib) declines, $S N P U$ declines and banks will need to attract additional foreign reserves, and, through the process described earlier, the increased demand for US\$ reserves raises interest rates. The increase in the interest rate that arises from the credit expansion, regardless of the expansion's cause, can be characterized as 'natural' since part of the liquidity generated by credit will be converted into US\$ and Mexico cannot 'produce' dollars.

Finally, the impact from an increase in the rate of interest will depend on whether or not firms have access to foreign credit. Large multinational firms tend to prefer (and access) US\$ foreign credit, and the increase in US\$ inflows will support a more than proportional increase in peso deposits. On the other hand, firms without access to foreign credit will tend to reduce demand for commercial bank credit. The result of these two actions will cause commercial bank liabilities to grow more than their credits, therefore SNPU will decrease, and the inflow of US\$ by large firms will put pressure on the interest rate to fall, thus starting another cycle. In the next section, we formally test the relationship between the (representative) interest rate and $S N P U$, as well as the other hypotheses outlined in the paper.

\section{THE ENDOGENOUS-MONEY PROCESS IN MEXICO: EMPIRICAL EVIDENCE}

Based on the analysis of the institutional differences for the endogenous-money process in Mexico, we outline three propositions: (i) the peso is used predominantly as a medium of exchange; (ii) credit creation, hence liquidity creation, is constrained by the

17. When commercial banks sell excess US\$ in local markets, Banxico can either accumulate foreign reserves $(F x)$ or sterilize them. In the first case, the monetary base $(B)$ will also increase; $S N P U$ does not change. If Banxico chooses to sterilize by open-market operations, SNPU is again unchanged as the increase in the monetary base $(B)$ is offset by a decrease in securities $(G S c b)$. However, when the central bank chooses to sterilize the accumulation of foreign reserves in this way, the increase in $F x$ is not designed to foster aggregate demand. 
need for US\$ reserves; and (iii) the interest rate is influenced by the relative needs of the banking system for peso and US\$ reserves.

\subsection{The peso as a medium of exchange}

Given the presence and role of the US\$ as the primary store of value, we should expect a close relationship between GDP and liquidity, similar to what the quantity theory suggests:

$$
L=D D+B=(1 / v) Y
$$

where $Y$ is aggregate income and $v$ is the velocity of liquidity circulation. Since the 1995 crisis, the velocity of $L$ has been relatively stable, falling within a range of 4 to 5.5 (Figure 4). The relative stability of velocity suggests a strong relationship between $L$ and GDP, and the estimated correlation is near one (Table 1).

Endogenous-money theory suggests changes in demand (GDP) should lead to changes in $L$. We tested the relationship between $L$ and GDP using lagged values; however, we found no statistical support for the hypothesis that GDP explains $L$ (or vice versa), which is most likely due to autocorrelation. ${ }^{18}$

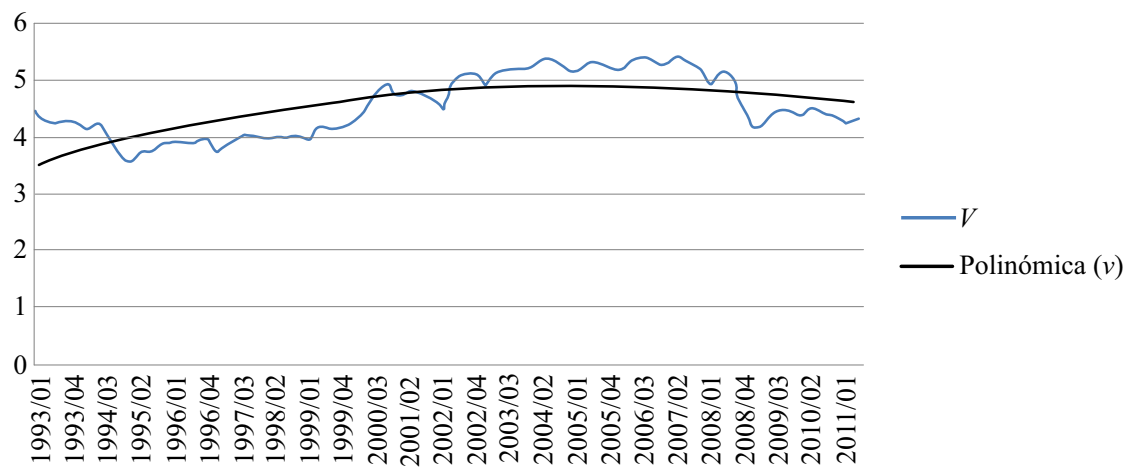

Figure 4 Velocity of liquidity

Table 1 Correlations between GDP (PIB) and liquidity

\begin{tabular}{llcc}
\hline & & $P I B r$ & $L q$ \\
\hline PIBr & Pearson correlation & 1 & $0.957^{* *}$ \\
& Sig. (2-tailed) & \multicolumn{2}{c}{-0.000} \\
\multirow{4}{*}{$L q$} & $N$ & 91 & 91 \\
& Pearson correlation & $0.957^{* *}$ & 1 \\
& Sig. (2-tailed) & 0.000 & \multicolumn{2}{c}{-} \\
& $N$ & 91 & 91 \\
\hline
\end{tabular}

Note: ** Correlation is significant at the 0.01 level (2-tailed).

18. Interestingly, we tested the relationship between $L$ and real interest rates and found significance at the 90 percent level, but the coefficient was positive. This could be a result of the relationship between interest rates, US\$, and $L$ which we evaluate in the next two sections. 


\subsection{Subordinated endogenous liquidity}

Here, we test the proposition that the need for US\$ reserves by the banking system creates an additional constraint on credit and liquidity creation. Foreign currency operates directly by creating bank deposits and indirectly through supplying US\$ reserves required by the Mexican banking system to support additional credit creation; therefore, we expect a positive relationship between $L$ and US\$ flows:

$$
L=\alpha+\beta(U S)+\varepsilon .
$$

Since Mexico's largest external market is the US, we use exports $(X)$ and the capitalaccount balance $(B K)$ as proxies for US\$ inflows. We use quarterly data for $X$ and $L$ from the Instituto Nacional de Estadistica y Geografic (INEGI) and Banxico respectively.

The results indicate a positive relationship between $X$ and $L$, which is statistically significant at the 95 percent confidence level, using both a lagged linear regression model and a model with first differences (Table 2). ${ }^{19}$ We did similar tests using the variable $B K$ (not shown), but found no evidence that capital inflows influence $L$. While we expected to find supportive evidence of a positive relation between $B K$ and $L$, this might not be the case if capital inflows are related to asset purchases. Future efforts are needed to evaluate this issue.

\subsection{The interest rate and SNPU}

We argue that the interest rate defines the balance between liquidity generated by domestic sources $(L n)$ and liquidity generated from foreign flows $(L x)$, and we attempt to capture this balance through the variable SNPU. The interest rate will oscillate in relation to the level and origin of the flows of liquidity, but fluctuations in the interest rate induce a trade-off between the sources of liquidity expressed through variations in $S N P U$. The fluctuations in the sources of liquidity (projected on SNPU variations), and the corresponding adjustments of the interest rate, guarantee the endogenous generation of domestic and foreign reserves.

Figure 5 shows the monthly annualized interest-rate series (cetes) for the 28-day government bond, and the annual moving average of real monthly variations in

Table 2 Linear regression on $L$

\begin{tabular}{|c|c|c|c|c|c|c|c|}
\hline Dependent variables & $G D P$ & $X$ & $d X$ & $L(-1)$ & $(C)$ & \# Obs. & $R 2$ \\
\hline$L=f(X, L(-1), C)$ & - & $\begin{array}{l}0.3135 \\
(3.560)\end{array}$ & - & $\begin{array}{l}0.9163 \\
(30.04)\end{array}$ & $\begin{array}{c}23545.6 \\
(1.996)\end{array}$ & 90 & 0.998 \\
\hline$d L=f(d X, C)$ & - & - & $\begin{array}{l}0.3316 \\
(2.648)\end{array}$ & - & $\begin{array}{c}46311.8 \\
(6.922)\end{array}$ & 89 & 0.074 \\
\hline$L=f(G D P, L(-1), C)^{* *}$ & $\begin{array}{c}0.0021 \\
(0.386)^{*}\end{array}$ & - & - & $\begin{array}{l}1.0150 \\
(44.2)\end{array}$ & $\begin{array}{c}2977.6 \\
(0.231)^{*}\end{array}$ & 90 & 0.998 \\
\hline
\end{tabular}

Notes: Unstandardized coefficients; ( $t$-statistic in parentheses).

* No significance at 10 percent.

** Correlation between GDP (PIB) and liquidity $(L)=0.957$, and it is significant at the 0.01 level (2-tailed).

19. We included a one-period lag value of $L$ to eliminate serial correlation. 


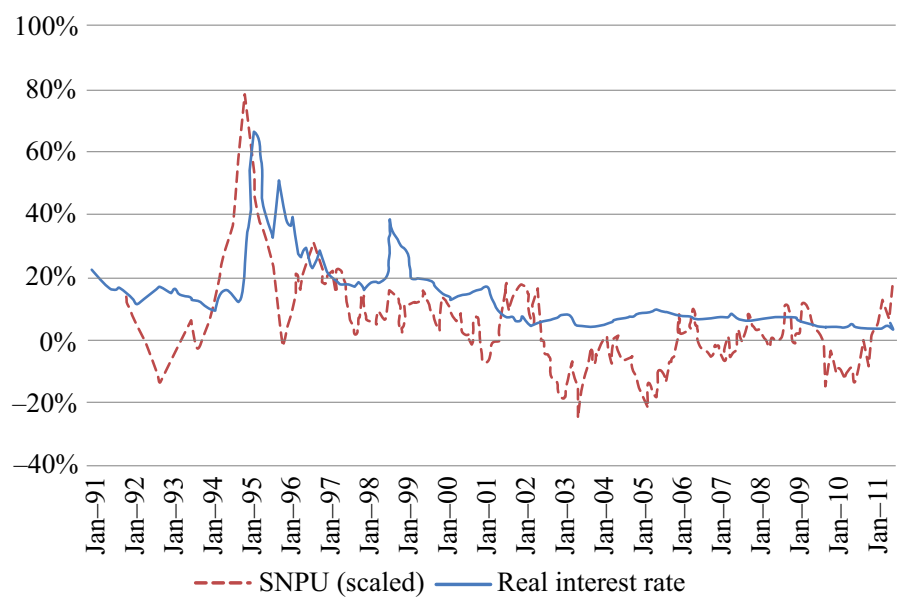

Source: Based on series published by INEGI, CNBV (Comision Nacional Bancaria y de Valories) y Banxico.

\section{Figure 5 Interest rate and SNPU}

SNPU (smSNPU) from January 1991 to November 2015. We use a moving average to show the cyclical relationship between SNPU and interest rates. Using the moving average of SNPU helps account for how the initial injection of US\$, which increases both Rib and SNPU, is associated with a drop in the interest rate. The cyclical movement expressed by smSNPU should allow us to capture the cyclical positive relation with the interest rate, as described in Section 3.4.

We evaluate the thesis two ways. First, we test the relation between interest rates and foreign-reserve balances held by commercial banks $(R i b)$ :

$$
i r=\alpha-\beta(R i b)+\varepsilon .
$$

We expect a negative sign since increased US\$ reserves support easy credit conditions, and banks will need to raise interest rates when US\$ reserves are insufficient. Second, we test the cyclical relationship between interest rates and $s m S N P U$. As described in Section 3.4, we expect $s m S N P U$ to be positively related to the interest rate over the credit cycle:

$$
\text { ir }=\alpha+\beta(\operatorname{smSNPU})+\varepsilon .
$$

For interest rates and $R i b$ we use a linear regression model and the results are supportive: a negative coefficient at a level of significance that could not be rejected (Table 3). We tested the relationship between $s m S N P U$ and the (annualized monthly) interest rate using a linear model with several different lag structures. The results are also supportive: the coefficient is positive and significant at the 90 percent confidence level (Table 3).

The results suggest that an increase in spending financed by domestic credit expansion can only be sustained if there is an autonomous and simultaneous expansion of US\$ inflows that is strong enough to provide the foreign reserves the credit expansion requires. The empirical evidence tends to support our contention that the Mexican economy is unable to self-finance its development because an expansion cannot be sustained through national credit without proportional responses of the interest rate 


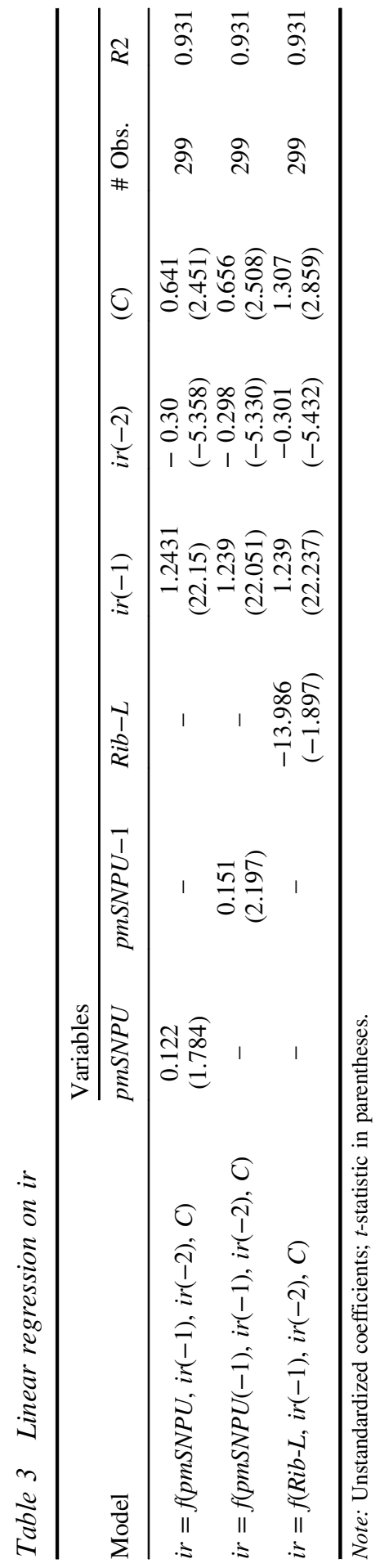


and the rate of exchange. Since credit in Mexico can only grow leveraged on the dollar, it is possible to say that the Mexican peso is a subordinated coin.

\section{CONCLUSION}

Based on the Post-Keynesian principle that money is endogenously created by demand-driven credit, we argue that the particular institutional characteristics of the monetary system in Mexico define a specific operative form of the endogenousmoney process. Specifically, commercial bank credit expansion requires both peso and US\$ reserves. Any model concerned with the creation and circulation of money in Mexico, then, must explicitly include the role of the US\$. Under the present institutional framework, the Mexican financial system cannot self-finance a sustained growth of aggregate demand because expansions require a concomitant flow of dollars. The interest rate is determined by the alternating dominant sources of liquidity, domestic commercial bank credit $(L n)$, and US\$ flows $(L x)$. As we have shown, without US\$ inflows, an increase in domestic credit will induce an increase in the interest rate which can constrain the expansion or engender a recession. If our explanation is correct, then it helps explain the observation that the growth rate of the Mexican economy has been persistently below the estimated BoP-constrained growth rate since 1995 . We intend to formally investigate the connection in future research.

Mexican institutional features also play an important role in the determination of the mechanism of liquidity cancellation. The principal mechanisms for withdrawing liquidity, excluding the conversion of pesos into dollars, are NMDs and regulatory government bonds, and neither of these instruments is directly linked to the cancellation of commercial-bank credit. Therefore, the finance-funding process described by the Post-Keynesian revolving fund theory does not adequately describe the process of liquidity withdrawal in Mexico. This characteristic highlights a significant weakness of the Mexican financial system: the lack of capital market mechanisms to complete the funding process initiated by domestic commercial-bank credit.

If our analysis is correct, then Mexico requires a financial development policy that incorporates an explicit strategy related to US\$ flows because of its indispensable role as a reserve currency in the banking system. In fact, administration of the interest rate by the central bank is only possible if it is operated simultaneously with a bank credit policy that acknowledges the important role of the US\$ in the credit-creation process. Lastly, broader development of Mexico's capital markets is necessary to replace NMDs and regulatory state bonds as liquidity withdrawal mechanisms.

\section{REFERENCES}

Araujo, R.A., M.S. de Paiva, and J.F. Santos (2016), 'The role of intermediate inputs in a multisectoral balance-of-payments-constrained growth model: the case of Mexico,' Working Paper, Presented at the 20th Conference of the Research Network Macroeconomics and Macroeconomic Policies, available at: https://www.boeckler.de/pdf/v_2016_10_22_araujo.pdf.

Cardim de Carvalho, F.J. (1997), 'Financial innovation and the Post Keynesian approach to the process of capital formation,' Journal of Post Keynesian Economics, 19(3), 461-487.

Castillo-Polanco, A.L. (2012), The Process of Injection, Circulation and Withdrawal of Liquidity, Spain: EAE Editorial Académica Espanola.

Davidson, P. (1986), 'Finance, funding, saving, and investment,' Journal of Post Keynesian Economics, 9(1), 101-110. 
Gouvêa, R.R. and G.T. Lima (2010), 'Structural change, balance-of-payments constraint, and economic growth: evidence from the multisectoral Thirlwall's law,' Journal of Post Keynesian Economics, 33(1), 169-204.

Ibarra, C.A. and R. Blecker (2014), 'Structural change, the real exchange rate, and the balance of payments in Mexico, 1960-2012,' available at: https://ideas.repec.org/p/amu/wpaper/2014-01. html.

Keynes, J.M. (1937), 'The general theory of employment,' Quarterly Journal of Economics, 51(2), 209-223.

Lavoie, M. (2001), 'The reflux mechanism and the open economy,' in L.-P. Rochon and M. Vernengo (eds), Credit, Interest Rates and the Open Economy: Essays on Horizontalism, Cheltenham, UK and Northampton, MA: Edward Elgar Publishing, pp. 215-242.

Levy-Orlik, N. (2012), 'Effects of financialization on the structure of production and nonfinancial private enterprises: the case of Mexico,' Journal of Post Keynesian Economics, 35(2), 235-254.

Levy-Orlik, N. and C. Dominguez-Blancas (2016), 'The operation of the Mexican banking system under foreign multinational corporations' control: new activities and traditional income,' International Review of Applied Economics, 30(4), 527-546.

Pollin, R. (1991), 'Two theories of money supply endogeneity: some empirical evidence,' Journal of Post Keynesian Economics, 13(3), 366-396.

Prebisch, R. (1949), 'The economic development of Latin America and its principal problems,' Report, UN.

Rochon, L.-P. and S. Rossi (2013), 'Endogenous money: the evolutionary versus revolutionary views,' Review of Keynesian Economics, 1(2), 210-229.

Rousseas, S. (1985), 'A markup theory of bank loan rates,' Journal of Post Keynesian Economics, 8(1), 135-144.

Thirlwall, A.P. (2011), 'Balance of payments constrained growth models: history and overview,' PSL Quarterly Review, 64(259), 307-351.

Thirlwall, A.P. and R. Dixon (1979), 'An export-led growth model with a balance of payments constraint,' in J. Bowers (ed.), Inflation, Development and Integration: Essays in Honour of A. J. Brown, London: University of Leeds Press, pp. 173-192.

Wray, L.R. (1998), Understanding Modern Money: The Key to Full Employment and Price Stability, Cheltenham, UK and Lyme, NH: Edward Elgar Publishing.

Wray, L.R. (2004), 'When are interest rates exogenous?' available at SSRN 1010158. 